\title{
Spontaneous Formation of Core@shell Co@Cr Nanoparticles by Gas Phase Synthesis
}

\author{
Jimena Soler-Morala ${ }^{1,2}$, Elizabeth M. Jefremovas ${ }^{1,3} \mathbb{C}^{\mathbb{D}}$, Lidia Martínez ${ }^{1, * \mathbb{C}}$, Álvaro Mayoral ${ }^{4,5,6}$, \\ Elena H. Sánchez ${ }^{7}$, Jose A. De Toro ${ }^{7}$ (D), Elena Navarro ${ }^{8,9}{ }^{\mathbb{D}}$ and Yves Huttel ${ }^{1}$ (D) \\ 1 Instituto de Ciencia de Materiales de Madrid, Consejo Superior de Investigaciones Científicas (ICMM-CSIC), \\ c/Sor Juana Inés de la Cruz, 3, 28049 Madrid, Spain; jimena.soler@imdea.org (J.S.-M.); \\ elizabma@ucm.es (E.M.J.); huttel@icmm.csic.es (Y.H.) \\ 2 IMDEA Nanociencia, c/Faraday, 9, 28049 Madrid, Spain \\ 3 Dpto. Ciencias de la Tierra y Física de la Materia Condensada, Universidad de Cantabria, \\ Avda. de los Castros, 48, 39005 Santander, Spain \\ 4 Institute of Nanoscience and Materials of Aragon (INMA), Spanish National Research Council (CSIC), \\ University of Zaragoza, 12, Calle de Pedro Cerbuna, 50009 Zaragoza, Spain; amayoral@unizar.es \\ 5 Laboratorio de Microscopias Avanzadas (LMA), University of Zaragoza, 50015 Zaragoza, Spain \\ 6 Center for High-Resolution Electron Microscopy (CћEM), School of Physical Science and Technology, \\ ShanghaiTech University, 393 Middle Huaxia Road, Pudong, Shanghai 201210, China \\ 7 Dpto. de Física Aplicada, Instituto Regional de Investigación Científica Aplicada (IRICA), \\ Universidad de Castilla-La Mancha, 13071 Ciudad Real, Spain; Elena.HSanchez@uclm.es (E.H.S.); \\ JoseAngel.Toro@uclm.es (J.A.D.T.) \\ 8 Instituto de Magnetismo Aplicado (IMA), UCM-ADIF, 28230 Las Rozas, Spain; enavarro@ucm.es \\ 9 Departamento de Física de Materiales, Universidad Complutense de Madrid (UCM), 28040 Madrid, Spain \\ * Correspondence: lidia.martinez@icmm.csic.es
}

Received: 26 October 2020; Accepted: 12 November 2020; Published: 1 December 2020

check for updates

\begin{abstract}
This work presents the gas phase synthesis of $\mathrm{CoCr}$ nanoparticles using a magnetron-based gas aggregation source. The effect of the particle size and $\mathrm{Co} / \mathrm{Cr}$ ratio on the properties of the nanoparticles is investigated. In particular, we report the synthesis of nanoparticles from two alloy targets, $\mathrm{Co}_{90} \mathrm{Cr}_{10}$ and $\mathrm{Co}_{80} \mathrm{Cr}_{20}$. In the first case, we observe a size threshold for the spontaneous formation of a segregated core@shell structure, related to the surface to volume ratio. When this ratio is above one, a shell cannot be properly formed, whereas when this ratio decreases below unity the proportion of $\mathrm{Cr}$ atoms is high enough to allow the formation of a shell. In the latter case, the segregation of the $\mathrm{Cr}$ atoms towards the surface gives rise to the formation of a shell surrounding the Co core. When the proportion of $\mathrm{Cr}$ is increased in the target $\left(\mathrm{Co}_{80} \mathrm{Cr}_{20}\right)$, a thicker shell is spontaneously formed for a similar nanoparticle size. The magnetic response was evaluated, and the influence of the structure and composition of the nanoparticles is discussed. An enhancement of the global magnetic anisotropy caused by exchange bias and dipolar interactions, which enables the thermal stability of the studied small particles up to relatively large temperatures, is reported.
\end{abstract}

Keywords: gas-phase synthesis of nanoparticles; cluster sources; core@shell nanoparticles; CoCr nanoparticles

\section{Introduction}

Materials at the nanoscale have an increasing demand due to the drastic changes in their properties caused by size and surface effects [1]. Some well-known examples of these changes in the material properties include optical [2], catalytic [3], thermal [4], and magnetic properties [5]. The reduced coordination of surface atoms and the high fraction of them in relation to volume yield a variety of 
surface magnetism effects [6,7]. In this novel magnetism, changes occurring in the surface atoms of nanoparticles of transition metals such as cobalt, iron, or nickel, including the relaxation of lattice parameters and increased density of states at the Fermi level due to their modified electronic structure, lead to enhanced atomic magnetic moments [8] with a higher orbital contribution [9-11]. For the nanoparticle (NP) size range where the number of surface atoms is comparable to that of their volume counterparts, any material in contact with the magnetic material influences the magnetic response, for instance through hybridization with the $3 \mathrm{~d}$ orbitals of the transition metals $[9,12]$. In addition, new phenomena characteristic of the nanoscale emerge, such as superparamagnetism [13]; giant magnetoresistance due to spin-dependent scattering [14,15]; or, in bimagnetic systems with components of different anisotropy, exchange coupling [16].

The magnetism of $\mathrm{CoCr}$ alloys is due to the ferromagnetism of $\mathrm{Co}$, with a critical superparamagnetic size of $9 \mathrm{~nm}$ at room temperature (RT), as Cr is an antiferromagnetic material with a Néel temperature of $311 \mathrm{~K}$ [17]. Most of the literature on magnetic studies of the CoCr system focuses on thin alternating $\mathrm{Co}-\mathrm{Cr}$ layers for applications in magnetic recording or microwave sensing [18-21]. However, to our knowledge, there are no fundamental studies on the magnetism of $\mathrm{CoCr} N P s$, whether alloyed or core@shell-structured.

At the nanoscale, structural and compositional details are of prime importance in assessing fundamental properties, as even small impurities can have a huge effect. In this context, Ion Cluster Sources (ICS), also called Gas Aggregation Sources (GAS), have gained increasing interest in the scientific community, as they allow the fabrication of nanoparticles under extremely clean conditions. In brief, ICS are high vacuum or ultra-high vacuum systems where a given material is atomized (by magnetron sputtering, thermal evaporation, arc discharge, laser ablation, etc.). The resulting atoms are then condensed into nanoparticles that are extracted from the ICS in the form of a NP beam, which is then directed to a surface were the NPs can land with a controlled energy. This gas phase synthesis enables the fabrication of pure nanoparticles of much interest for fundamental studies [22,23]. Here, the synthesis of NPs has been performed using a variant of the Haberland-type gas aggregation source [24]. Specifically, the NPs were grown using a multiple ion cluster source (MICS), which is an adaptation where the single magnetron is replaced by three independent magnetrons $[25,26]$. This modification has been shown to be very effective for the fabrication of nanoparticles with a tuneable chemical composition and structure [27]. In the current work, however, instead of using two magnetrons for the fabrication of the $\mathrm{CoCr}$ NPs, $\mathrm{CoCr}$ alloy targets were used with variable amounts of each element, and the versatility of the MICS (in particular regarding the injection of argon through different magnetrons) was exploited in order to study the formation of $\mathrm{CoCr}$ nanoparticles with different compositions and structures.

The properties of the grown NPs are discussed in the light of the nanoscale ordering of the constituent elements. In addition, the size of the NPs was adjusted in order to modify the ratio of surface-to-volume atoms and study the structural and magnetic properties of the NPs as a function of such a ratio. In this work, the magnetism of the interacting CoCr nanoparticles was evaluated considering a number of compositional and structural variations. The observed enhancement of the global anisotropy of the NPs is discussed in terms of the exchange bias generated, which increases the thermomagnetic stability, thus "beating the superparamagnetic limit" in small-sized Co NPs [16]. These results will be correlated with the chemical and structural characterization carried out by X-ray photoelectron spectroscopy (XPS) and Scanning High-Resolution Transmission Electron Microscopy (HR-STEM) with Electron Energy Loss Spectroscopy (EELS) for chemical identification.

\section{Materials and Methods}

Fabrication of the nanoparticles. The nanoparticles (NPs) were grown using a multiple ion cluster source (MICS), with 1" magnetrons, loaded with CoCr targets (Testbourne, Basingstoke, UK, purity 99.95\%) with variable amounts of $\mathrm{Cr}\left(\mathrm{Co}_{90} \mathrm{Cr}_{10}\right.$ and $\left.\mathrm{Co}_{80} \mathrm{Cr}_{20}\right)$. In the case of the $\mathrm{Co}_{90} \mathrm{Cr}_{10}$ target, the typical power applied to the magnetron was $14 \mathrm{~W}$, with an Ar flux of 5 or 10 standard cubic 
centimeters per minute ( $\mathrm{sccm}$ ) in the ignited magnetron and a total Ar flux of $80 \mathrm{sccm}$. In the case of the $\mathrm{Co}_{80} \mathrm{Cr}_{20}$ target, the typical power applied to the magnetron was $5 \mathrm{~W}$, with an Ar flux of $5 \mathrm{sccm}$ in the ignited magnetron and a total Ar flux of $80 \mathrm{sccm}$. The base pressure of the system was below $5 \times 10^{-10}$ mbar.

The NPs produced with the MICS were deposited in an annex chamber (see Figure S1) either on flat $\mathrm{Si}(100)$ polished wafers with a roughness below $1 \mathrm{~nm}$ (UniversityWafer Inc., South Boston, MA, USA) or on TEM grids made of ultrathin carbon film on holey carbon support film on copper 400-mesh grids (Ted Pella Inc., Redding, CA, USA). The morphological, structural, chemical, and magnetic characterizations of the NPs were performed ex situ via atomic force microscopy (AFM), scanning transmission electron microscopy (STEM), X-ray photoemission spectroscopy (XPS), and a Superconducting QUantum Interference Device (SQUID). Different samples were grown for each characterization technique, adjusting the deposition time depending on the number of NPs required for each technique.

Atomic Force Microscopy (AFM). An Icon Nanoscope (Veeco) microscope in dynamic mode (soft tapping mode) was used for keeping the excitation frequency constant. Commercial AFM tips from Next-Tip were used. These are silicon tips with a capping of Au NPs with a typical radius of less than $3 \mathrm{~nm}$ and a resonance frequency $\left(f_{0}\right)$ and spring constant $(k)$ of $\approx 280 \mathrm{kHz}$ and $\approx 42 \mathrm{~N} / \mathrm{m}$, respectively. The analysis of the images was carried out using the WSxM software [28] and homemade macros operated in Igor Pro.

Scanning Transmission Electron Microscopy (STEM) observations were performed using a FEI-TITAN X-FEG transmission electron microscope in the STEM mode, operated at $300 \mathrm{kV}$. The images were acquired using a high-angle annular dark field (HAADF) detector. The microscope was equipped with a monochromator, the Gatan Energy Filter Tridiem 866 ERS; a spherical aberration corrector (CEOS) for the electron probe $\left(\mathrm{C}_{\mathrm{s}}\right.$-corrected), allowing an effective $0.08 \mathrm{~nm}$ spatial resolution; and an energy dispersive $\mathrm{X}$-ray detector for the EDS analysis. The chemical identification of the elements was carried out by Electron Energy Loss Spectroscopy (EELS).

X-ray photoelectron spectroscopy (XPS) was carried out ex situ in a separate UHV chamber, with a base pressure of $10^{-10}$ mbar, equipped with a hemispherical electron energy analyzer (SPECS Phoibos 150 spectrometer) and a delay-line detector using a monochromatic Al- $\mathrm{K}_{\alpha}(1486.74 \mathrm{eV}) \mathrm{X}$-ray source. Spectra were obtained at a $60^{\circ}$ emission take-off angle. Wide scans were recorded using an energy step of $0.5 \mathrm{eV}$ and a pass-energy of $40 \mathrm{eV}$. Higher energy resolution core level spectra were recorded using an energy step of $0.1 \mathrm{eV}$ and a pass-energy of $20 \mathrm{eV}$ at selected core levels: $\mathrm{Co} 2 \mathrm{p}, \mathrm{Cr} 2 \mathrm{p}$, and $\mathrm{O} 1 \mathrm{~s}$. The absolute binding energies of the photoelectron spectra were determined by referencing the $\mathrm{Cr} 2 \mathrm{p}$ peak at $576.4 \mathrm{ev}$ [29]. Data processing was performed using the CasaXPS software (Casa software Ltd., Cheshire, UK). Ion sputtering was performed by $\mathrm{Ar}^{+}$sputtering at $1.4 \mathrm{keV}$ at different sputtering times $(0,15,75,135,255$, and $375 \mathrm{~min})$, with a current measured of $0.67 \mu \mathrm{A}$.

Magnetic measurements. The magnetic characterization was carried out using a MPMS-5S and a MPMS-XL5 SQUID magnetometer with the EverCool system (Quantum Design), which can provide a maximum field of $50 \mathrm{kOe}$ and with a broad temperature working range from $2 \mathrm{~K}$ to $400 \mathrm{~K}$. Hysteresis loops at different temperatures and thermal dependence magnetization after field-cooled (FC, applying a magnetic field while cooling) and zero-field cooled (ZFC, no magnetic field applied during cooling) protocols were performed. The diamagnetic contribution was systematically subtracted from the silicon substrates.

\section{Results}

\subsection{Morphological and Structural Characterization}

One of the aims of this study was to investigate the evolution of the NPs' structure and composition as a function of their size starting from alloyed targets. Initially, two kind of samples were prepared using a $\mathrm{Co}_{90} \mathrm{Cr}_{10}$ target, varying the Ar flux through the magnetron in use (5 and $10 \mathrm{sccm}$ ) and 
keeping the other fabrication parameters fixed in order to obtain different nanoparticle sizes without a modification of the applied power. Although one of the parameters most used to modify the size of nanoparticles is the applied power, here we have chosen to keep the same power applied to the magnetron in order to avoid differences in the energy supplied to the nanoparticles during their growth, which can condition their final structure [30]. The nanoparticle size was systematically determined by AFM by measuring the height of the nanoparticles from several images, such as the ones depicted in Figure $1 \mathrm{a}, \mathrm{c}$ and obtaining statistics over 1600 NPs per sample. The resulting height distributions were fitted to a Log-Normal function (Figure 1b,d), as expected using this fabrication method [31], and the extracted mean NP size and their respective standard deviation were found to be $5.59 \pm 0.05 \mathrm{~nm}$ for the sample fabricated with $10 \mathrm{sccm}$ of Ar and $6.91 \pm 0.03 \mathrm{~nm}$ when $5 \mathrm{sccm}$ was used, keeping the total Ar flux in the system constant.
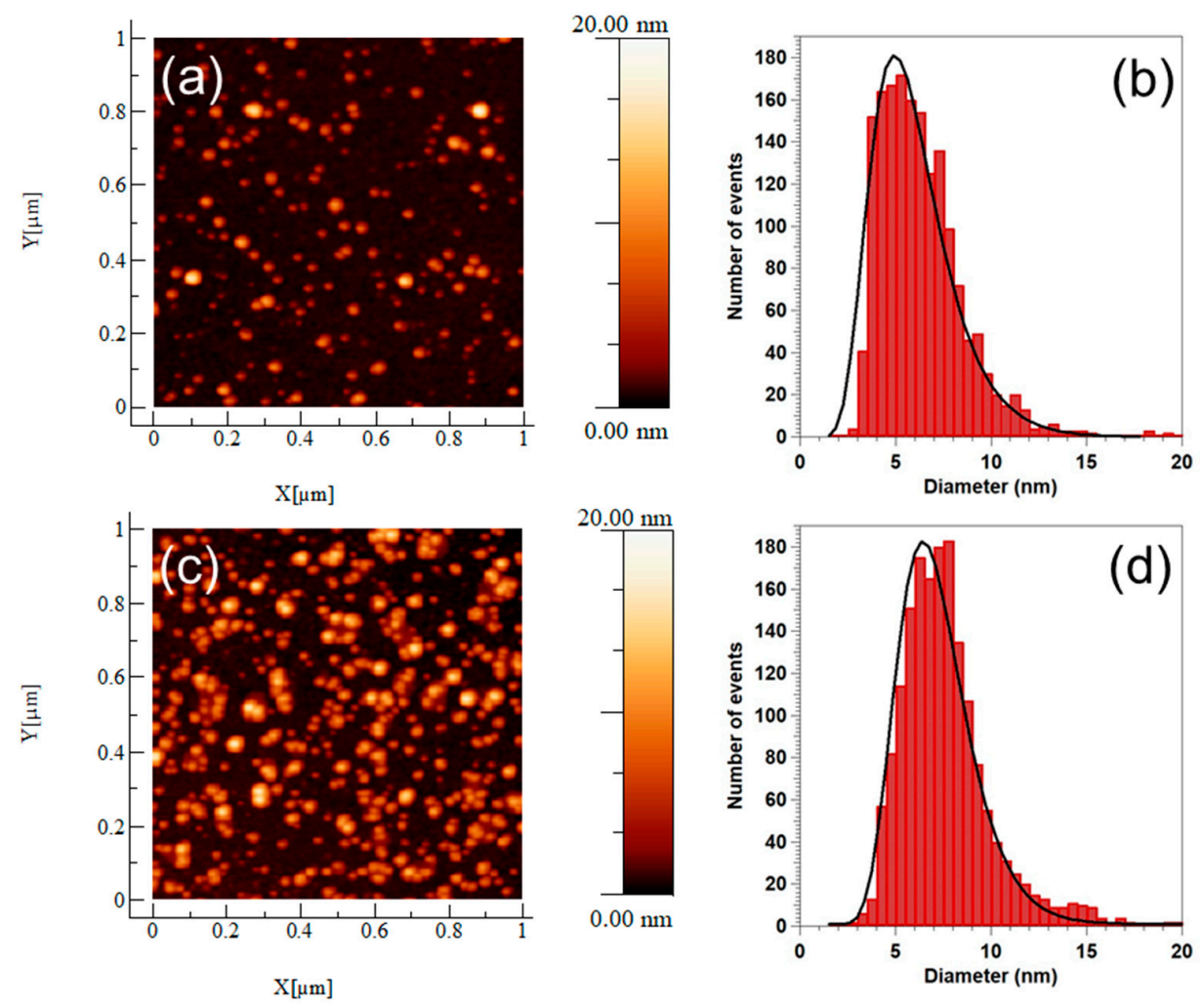

Figure 1. (a) AFM image of $1 \mu \mathrm{m}^{2}$ of a Co@Cr nanoparticle (NP) deposit performed injecting $10 \mathrm{sccm}$ argon into the magnetron loaded with the $\mathrm{Co}_{90} \mathrm{Cr}_{10}$ target, (b) height distribution and Log-Normal fitting extracted form (a). The mean size of the NPs is $\approx 5.6 \mathrm{~nm}$, (c) the AFM image of $1 \mu \mathrm{m}^{2}$ of a Co@Cr NP deposit performed with $5 \mathrm{sccm}$ of argon, (d) height distribution and Log-Normal fitting extracted form (c). The mean size of the NPs is $\approx 6.9 \mathrm{~nm}$.

Therefore, as can be observed from Figure 1, the modification of the argon flux injected in the working magnetron has a clear influence on the size of the resulting NPs. In previous works using MICS [32,33], we reported how, for the same total Ar flux through the three magnetrons of the MICS, the lower amount of Ar injected through the operating magnetrons leads to bigger NPs.

Spherical aberration-corrected (Cs-corrected) STEM was used for a deeper analysis of the structure and composition of both kinds of NPs. This analysis revealed the dependence of the structure on the NP size. The Cs-corrected high resolution STEM (HR-STEM) images of the smallest NPs $(d \approx 5.6 \mathrm{~nm})$ evidenced the presence of different crystalline domains (Figure 2a), in which EELS analysis revealed a certain $\mathrm{Cr}$ segregation (Figure 2b). The homogeneous presence of oxygen indicated that most of $\mathrm{Cr}$ and Co were oxidized, although the presence of a small metallic Co core could not be completely discarded. The origin of the oxygen arises from air exposure due to ex situ analysis. On the contrary, 
the Cs-corrected HR-STEM data of the biggest NPs $(\mathrm{d} \approx 6.9 \mathrm{~nm})$ revealed the spontaneous migration of $\mathrm{Cr}$ atoms towards the surface, creating a well-defined shell around a Co core. In this case, the shell could protect the Co core in its metallic state, which explains the contrast difference between the shell and the core, as the former appears with a lower intensity associated with the lower atomic number of oxygen [34]. This shell seems to be formed by small rounded crystallites of $1-2 \mathrm{~nm}$, resulting in a homogenous shell with distinct crystallographic domains in what resembles a petal structure. The EELS analysis revealed that $\mathrm{Co}$ is also present in the oxidized shell, but at a lower concentration (Figure 3), and the size of this shell for the $\mathrm{Co}_{90} \mathrm{Cr}_{10}$ has been measured to be $2.72 \pm 0.63 \mathrm{~nm}$.
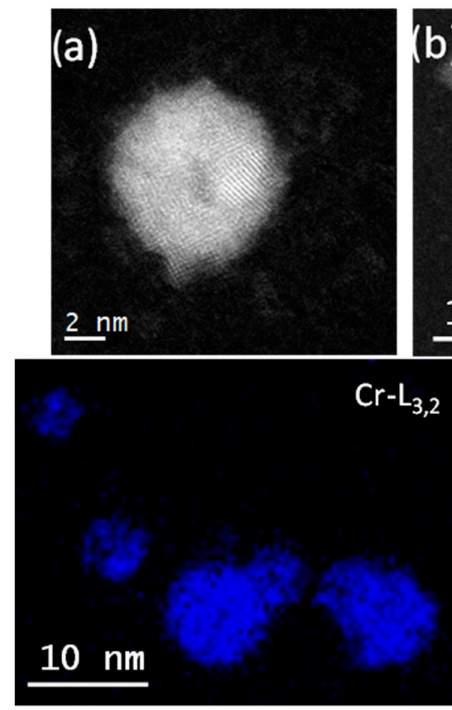
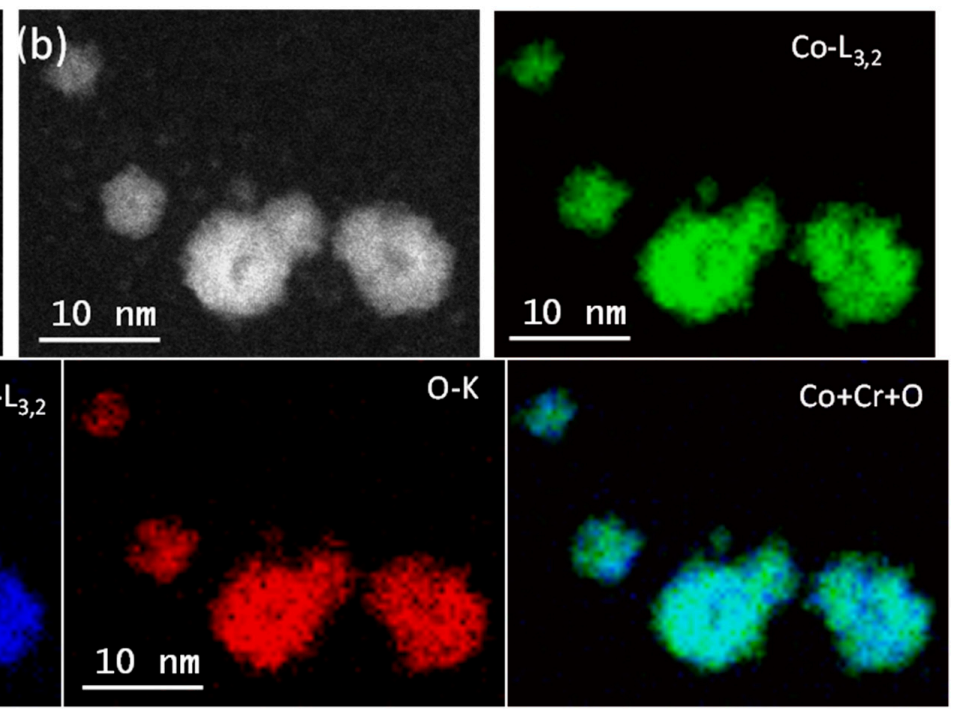

Figure 2. $\mathrm{C}_{\mathrm{s}}$-corrected Scanning High-Resolution Transmission Electron Microscopy (HR-STEM) data corresponding to the small CoCr NPs $(5.6 \mathrm{~nm}$ ). (a) High magnification of an isolated NP, exhibiting its different crystal domains. (b) Several CoCr NPs and their corresponding Electron Energy Loss Spectroscopy (EELS) chemical maps.
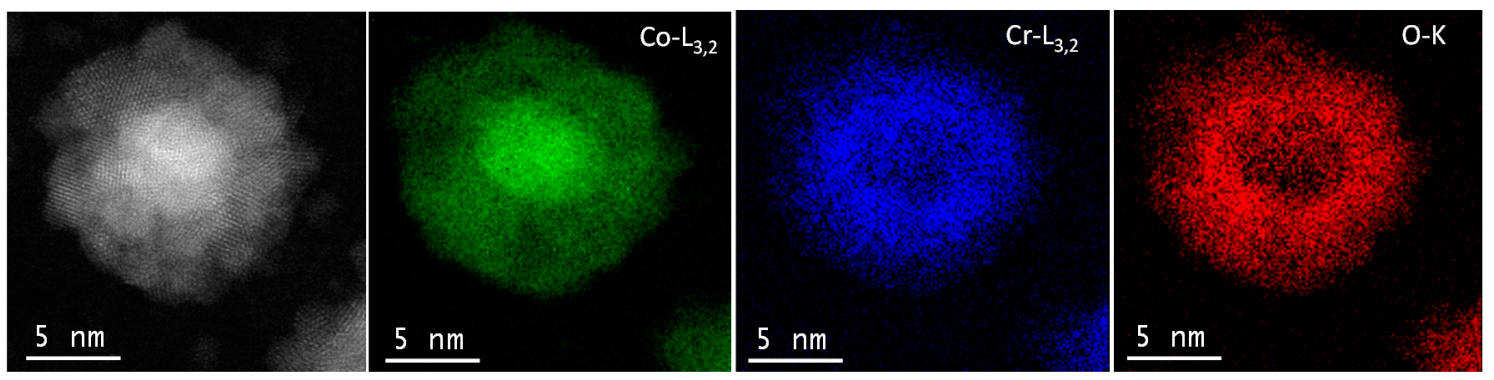

Figure 3. $\mathrm{C}_{\mathrm{s}}$-corrected HR-STEM data corresponding to the bigger CoCr NPs $(6.9 \mathrm{~nm})$. A high-magnification image is presented together with the corresponding EELS chemical maps.

According to these results, it seems that a minimum NP size is needed in order to spontaneously generate a core@shell structure without the need of any further treatment. Previous works needed, for instance, a thermal treatment, either in flight [35] or post deposition [36], to create well-defined core@shell NPs. However, the spontaneous formation of this structure clearly simplified the fabrication process. This minimum size is slightly below the $8 \mathrm{~nm}$ reported by Koten et al. [37] for similar bimetallic systems. Given that the power used for the fabrication of both NP types was the same, a similar thermal energy should then be expected. Segregation is a size-dependent phenomenon [38], and lowering the free energy for phase separation is significant in this size range [39]. In the case of the smaller NPs, the partial segregation of $\mathrm{Cr}$ in certain parts of the surface could suggest that an initial shell formation occurs. Nevertheless, it would not be enough for a complete shell formation, as in the case of the bigger 
NPs. In addition, the lattice mismatch between both elements implies that segregation would be more favorable than alloy formation, acting in favor of a core@shell configuration. Previous studies have reported the segregation during the gas-phase synthesis of NPs of ferromagnetic elements ( $\mathrm{Fe}, \mathrm{Co})$ and noble metals $(\mathrm{Au}, \mathrm{Ag})[40,41]$. However, in that case the differences among the characteristics of the two elements, in terms of atomic size and surface energy, were distinctively larger than those between $\mathrm{Co}$ and $\mathrm{Cr}$; in fact, they constitute a model system of bimetallic segregated structures [42], as shell formation is strongly favored in that case.

In addition, it is well known that the surface to volume ratio in this size range is highly variable [1]. Assuming that the nanoparticles are spherical, the surface-to-volume ratio of the smaller NPs would be higher than 1 (calculated with the NP radius extracted from the AFM analysis), meaning that there are more atoms at the surface than in the volume (i.e., more than $50 \%$ are surface atoms). However, as the percentage of atoms extracted from the sputtering target is only $10 \% \mathrm{Cr}$, even taking into account the higher sputtering yield of $\mathrm{Cr}$, there are not enough $\mathrm{Cr}$ atoms to create a complete $\mathrm{Cr}$-rich shell covering a Co core, even assuming a complete diffusion of $\mathrm{Cr}$ at the surface of the nanoparticles. Nevertheless, the diffusion of the $\mathrm{Cr}$ atoms at the NPs surface is observed through the presence of $\mathrm{Cr}$-enriched regions, as shown in Figure 2. It seems then that $\mathrm{Cr}$ displays a clear tendency to migrate towards the surface. In the case of bigger NPs (Figure 3), the surface atoms represent only $14 \%$ of the total, which is quite close to the $10 \% \mathrm{Cr}$ atoms available. Therefore, a smaller proportion of atoms are needed to create a Cr-enriched shell in comparison to smaller NPs. It is well known that the thermalization of the nanoparticles takes place through the collisions with the cooling gas (argon, in the case of this work) [43]. Given that the same argon flux was used in the fabrication of both types of nanoparticles, the available argon gas for the cooling process is identical. As the bigger NPs have a higher stored energy (the energy is proportional to the number of atoms in the NP) the cooling process is slower, which favors the diffusion process of the Cr atoms to the surface of the NPs.

\subsection{Magnetic Characterization}

For the study of the magnetic behavior of the fabricated systems, a single nominal monolayer of NPs (1 ML) was deposited. Consequently, the deposits are subjected to interparticle interaction effects [44]. Dipolar interactions will, on the one hand, increase the blocking temperature [45] and, on the other hand, reduce the coercivity of the loops measured in the blocked regime [46]. There may also be interparticle exchange interactions as a consequence of the connectivity effects between antiferromagnetic shells in contact $[47,48]$.

Figure $4 \mathrm{a}$ shows the hysteresis loops registered at $5 \mathrm{~K}$ in both samples after cooling in a field $\mathrm{H}=50 \mathrm{kOe}$. The coercivity $\left(\mathrm{H}_{\mathrm{c}}\right)$ and exchange bias $\left(\mathrm{H}_{\mathrm{ex}}\right)$ fields for the NPs with $\mathrm{d}=5.6 \mathrm{~nm}$ were found to be 4170 and 1820 Oe, respectively, whereas for the deposit of NPs with $\mathrm{d}=6.9 \mathrm{~nm}, \mathrm{H}_{\mathrm{c}}=3810$ Oe and $\mathrm{H}_{\mathrm{ex}}=1510$ Oe were measured.
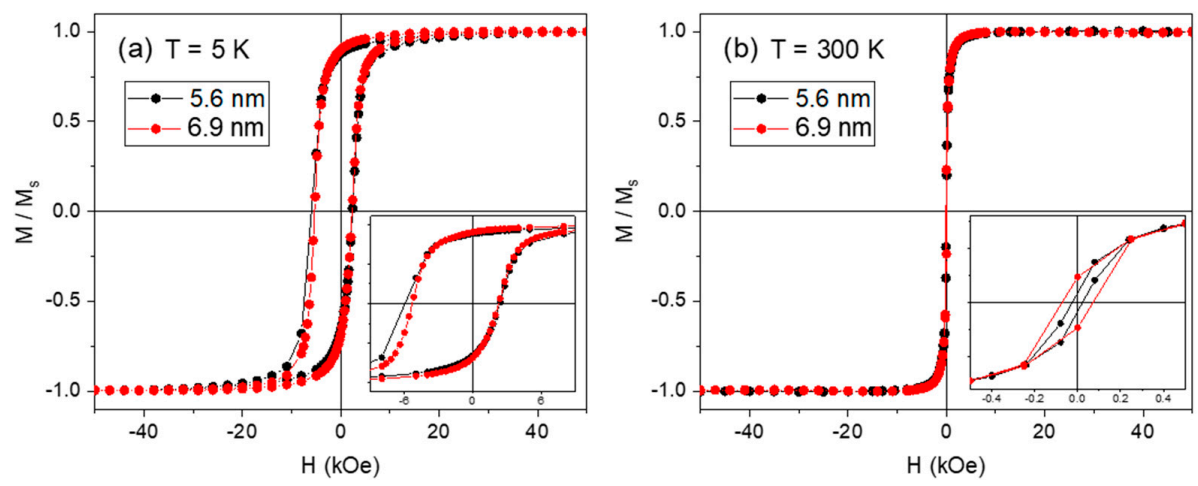

Figure 4. Normalized hysteresis loops measured after cooling in $\mathrm{H}=50 \mathrm{kOe}$ at (a) $5 \mathrm{~K}$ and (b) $300 \mathrm{~K}$ for CoCr NPs $5.6 \mathrm{~nm}$ (black) and $6.9 \mathrm{~nm}$ (red) in diameter. The insets show the detail of the central region of the loops, where a strong exchange bias effect can be observed at $\mathrm{T}=5 \mathrm{~K}$. 
As these small particles are magnetic monodomains [49] well blocked at $5 \mathrm{~K}$, the coercivity should increase with particle size. Yet, the opposite trend is observed. This discrepancy is associated with the inner structure of the NPs unveiled by the above EELS mappings. The bigger NPs present a well-defined core@shell structure with Co as the main constituent in the core, and a surrounding shell comprising $\mathrm{Co}, \mathrm{Cr}$, and $\mathrm{O}$. The observation of a coercive field in these NPs indicates that the Co core is metallic. This is probably due to the protective shell, which prevents core oxidation. The smaller NPs present a more heterogeneous structure, where the incomplete $\mathrm{Cr}$ shell allows for a higher degree of Co oxidation and, thus, a higher fraction of antiferromagnetic Co oxide, favoring, in turn, a stronger exchange coupling [50,51]. Moreover, for a given antiferromagnetic shell, the interfacial nature of the exchange bias effect yields a dependence on the reciprocal of the magnetic moment of the core [52], also explaining the lower $\mathrm{H}_{\mathrm{ex}}$ in the larger particles. Exchange coupling is well known to enhance the coercivity of magnetic particles through an increase in the effective anisotropy [52], thus accounting for the observed values.

In contrast, at $300 \mathrm{~K}$ (Figure $4 \mathrm{~b}$ ) the $\mathrm{H}_{\mathrm{c}}$ of the bigger NPs is slightly higher than that of the smaller NPs. In both cases, exchange bias is reduced to zero, indicating that the phase (or phases) responsible for the exchange coupling must have a Néel temperature, $\mathrm{T}_{\mathrm{N}}$, or a blocking temperature of the antiferromagnetic grains lower than $300 \mathrm{~K}$.

Neither the ZFC nor the FC magnetization curves, measured up to RT, showed a maximum from which a blocking temperature $\left(T_{B}\right)$ could be extracted (see Figure S2, Supplementary Material). This confirms the blocked state at room temperature of our NP systems, with a mean size of 6-7 nm. The ferromagnetic behavior (blocked regime) of such small particles at room temperature (RT) is likely to be associated to the metallic cobalt core assisted by interparticle interactions and by the stabilization of the surface magnetic moments, thanks to the presence of the surrounding phases [53]. The temperature dependence of the coercivity above $150 \mathrm{~K}$ is plotted in Figure 5, showing a progressive reduction and vanishing close to $400 \mathrm{~K}$. At $150 \mathrm{~K}$, where the exchange bias field is negligible, the coercivity of the deposit of $6.9 \mathrm{~nm}$ NPs is higher than that of $5.6 \mathrm{~nm}$ particles, as expected strictly from the particle size dependence of coercivity.

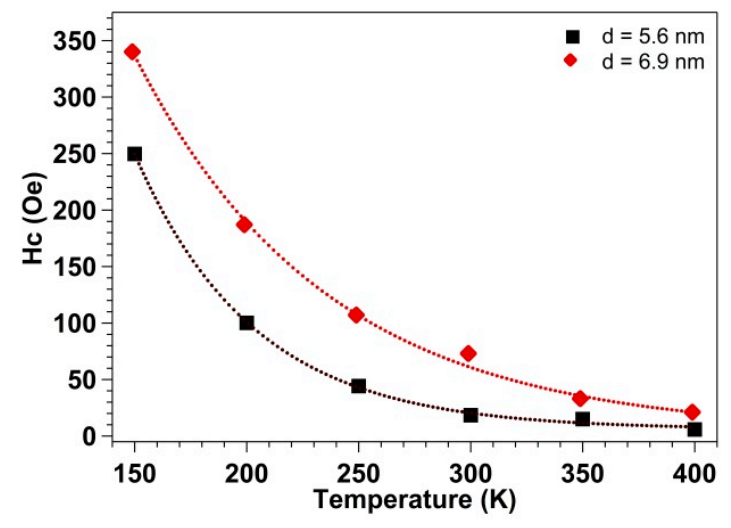

Figure 5. Coercive field dependency on temperature for both samples $(5.6 \mathrm{~nm}$, black squares, and $6.9 \mathrm{~nm}$, red diamonds, in diameter).

\subsection{Chemical Characterization}

In order to extract more information about the chemistry and electronic structure of the core@shell nanoparticles, an XPS analysis was carried out in a multilayer of Co@Cr NPs. A depth profile analysis was performed on the multilayer in order to obtain information on the whole nanostructured system. The sputtering rate is $0.4 \AA / \mu \mathrm{A} \cdot \mathrm{min}$ for continuous thin films [54]. Although it is not possible to establish a direct correlation between this value and a porous nanostructured coating, the longest sputtering time used of 375 min ensures that we managed to remove at least one NP layer during the sputtering process. Figure $\mathrm{S} 3$ shows the evolution of the main constituents at different sputtering times. 
Figure $6 \mathrm{a}$ shows the analysis of the Co $2 \mathrm{p}$ core-level peak. The fitting was performed using four doublets and was identified using the binding energy (BE) of its $2 \mathrm{p}_{3 / 2}$ component. The first doublet at $777.7 \pm 0.5 \mathrm{eV}$ corresponds to metallic cobalt [55]. The intensity of this peak is increased with argon sputtering, as expected from a core@shell structure with a metallic cobalt core. The second doublet at $779.9 \pm 0.1 \mathrm{eV}$ is usually attributed to cobalt oxides [55]. According to the literature, $\mathrm{CoO}$, $\mathrm{Co}_{2} \mathrm{O}_{3}$, or $\mathrm{Co}_{3} \mathrm{O}_{4}$ are present in this $\mathrm{BE}$ range [55-57]. Besides, when cobalt is present in $\mathrm{Co}-\mathrm{Cr}$ spinels $\left(\mathrm{CoCr}_{2} \mathrm{O}_{4}\right)$ it can be included in this narrow $\mathrm{BE}$ range. Consequently, the presence of any of these oxides cannot be ruled out; the coexistence of more than one of them is likely [55,58,59]. However, the presence of a satellite at $786.5 \pm 0.1 \mathrm{eV}$ at all depths suggests the presence of $\mathrm{Co}$ in the form of $\mathrm{CoO}$ among these possible oxide mixtures [59]. Finally, the fourth doublet at $781.2 \pm 0.4 \mathrm{eV}$ corresponds to $\mathrm{Co}(\mathrm{OH})_{2}$ [59]. The peak intensity of this component decays exponentially with the sputtering time. Thus, it is considered that this cobalt hydroxide is formed at the surface of the NPs due to atmospheric exposure. A detailed evolution of the metallic, oxide, and hydroxide components as a function of the sputtering time is displayed in Supplementary Figure S4.
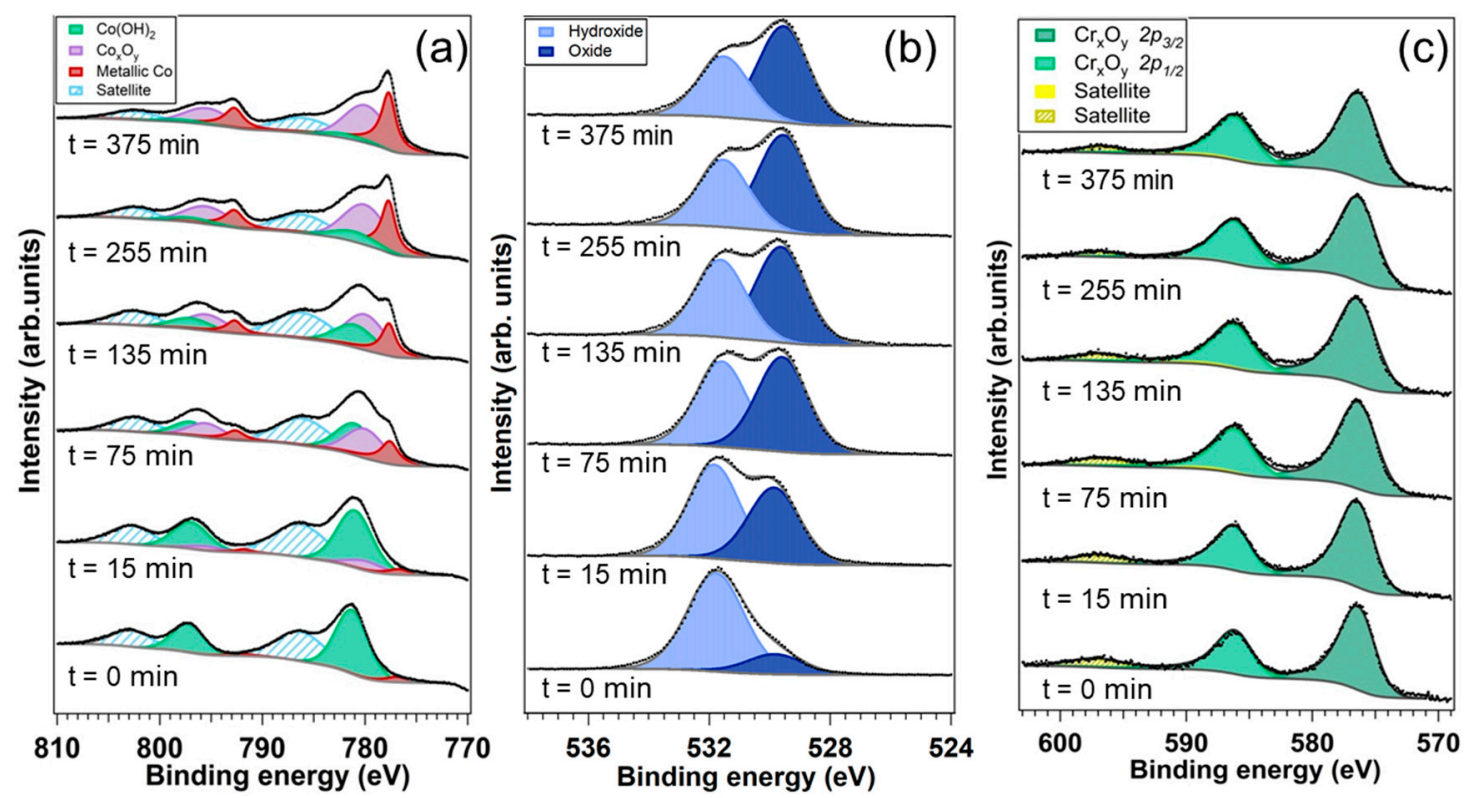

Figure 6. Analysis of the (a) Co 2p, (b) O 1s, and (c) $\mathrm{Cr} 2 \mathrm{p}$ core-level peaks as a function of the sputtering time.

Figure $6 \mathrm{~b}$ presents the evolution of the $\mathrm{O} 1 \mathrm{~s}$ core-level peak with the sputtering time. The spectra were fitted using two components: The first one, at $529.5 \pm 0.2 \mathrm{eV}$, can be associated with metallic oxides. The second, at $531.8 \pm 0.2 \mathrm{eV}$, can be attributed to metallic hydroxides. The compositional ratio of the hydroxide/oxide components in $\mathrm{O} 1 \mathrm{~s}$ follows the same tendency as the hydroxide/oxide component evolution in the Co $2 p$ spectra (Figure S4).

Finally, the analysis of the $\mathrm{Cr} 2 \mathrm{p}$ core-level spectra revealed the complete oxidation of chromium, irrespective of the sputtering time (Figure $6 \mathrm{c}$ ). A single doublet was used for the fitting, with a BE of the $2 \mathrm{p}_{3 / 2}$ component at $576.5 \pm 0.1 \mathrm{eV}$, which can be attributed to $\mathrm{Cr}^{3+}$ as a constituent of a chromium oxide $\left(\mathrm{Cr}_{\mathrm{x}} \mathrm{O}_{\mathrm{y}}\right)$ or as a part of a mixed oxide $\mathrm{Co}-\mathrm{Cr}\left(\mathrm{CoCr}_{2} \mathrm{O}_{4}\right)$. As for the case of the $\mathrm{Co} 2 \mathrm{p}$, neither of these species can be discarded. The small satellite at $588.5 \pm 0.1 \mathrm{eV}$ is characteristic of $\mathrm{Cr}_{2} \mathrm{O}_{3}$ and, therefore, at least the presence of this oxide can be confirmed. On the contrary, neither the component associated to $\mathrm{Cr}^{0}$ nor the one of $\mathrm{Cr}^{6+}$ could be detected [55].

In summary, the XPS analyses are consistent with a core@shell structure in which a metallic Co core is surrounded by a shell composed of $\mathrm{Co}$ and $\mathrm{Cr}$ oxides and a surface enriched in $\mathrm{Co}(\mathrm{OH})_{2}$ due to atmospheric exposure. Both elements, $\mathrm{Cr}$ and $\mathrm{Co}$, have a strong tendency to become oxidized. 
According to the XPS analysis, $\mathrm{Cr}$ is mainly found as $\mathrm{Cr}^{3+}$ and $\mathrm{Co}^{2} \mathrm{Co}^{2+}$, which means that $\mathrm{Cr}$ has one unpaired d electron more and, therefore, a higher tendency to get oxidized. Considering the fact that $\mathrm{Cr}$ is mainly located on the surface, and in form of chromium oxide, the possibility of the formation of a passive layer as the one $\mathrm{Cr}$ forms on stainless steels cannot be ruled out. Similar behavior has been reported on $\mathrm{CoCr}$ alloys with higher $\mathrm{Cr}$ contents, where a preferential $\mathrm{Cr}$ oxidation was observed in a surface enriched in $\mathrm{Cr}$ with Co depletion [60]. This is compatible with the presence of a metallic Co core inside the NPs.

\subsection{Nanoparticles with a Different Stoichiometry}

According to the previous sections, one strategy to obtain a core@shell structure consists of decreasing the ratio between surface and bulk atoms, while keeping fixed the ratio of $\mathrm{Co}$ and $\mathrm{Cr}$ atoms in the sputtering target. Nevertheless, an alternative and more common strategy consists of increasing the content of shell $(\mathrm{Cr})$ atoms. This latter approach has been adopted to fabricate NPs where a sputtering target with a higher content of $\mathrm{Cr}\left(\mathrm{Co}_{80} \mathrm{Cr}_{20}\right)$ has been used. The growth parameters were adjusted in order to obtain nanoparticles with a mean diameter close to $7 \mathrm{~nm}$ in order to allow the comparison with the previous Co@Cr NPs grown with the $\mathrm{Co}_{90} \mathrm{Cr}_{10}$ target.

Figure 7 shows a representative $\mathrm{C}_{\mathrm{s}}$-corrected HR-STEM image of a typical NP obtained in this new target. As can be observed, also in this case the core@shell structure is the most stable configuration. The EELS analysis revealed that Co is located within the NP core, while $\mathrm{Cr}$ is forming the shell, in the same way as for the previous NPs grown with the lower argon flux and the $\mathrm{Co}_{90} \mathrm{Cr}_{10}$ target. The presence of oxygen is also evidenced, preferentially where $\mathrm{Cr}$ is present, due to air exposure. From a statistical analysis of the TEM images, an average NP size of $7.7 \pm 0.5 \mathrm{~nm}$, with an average core $4.3 \pm 0.3 \mathrm{~nm}$, and a shell $1.70 \pm 0.11 \mathrm{~nm}$ can be extracted. Taking into account the target composition $\left(\mathrm{Co}_{80} \mathrm{Cr}_{20}\right)$ and considering that the core is formed by pure $\mathrm{Co}$, a core@shell structure should have a $5.4 \mathrm{~nm}$ diameter core with a shell of $0.55 \mathrm{~nm}$, i.e., three times smaller than the obtained shell. This mismatch could arise from the fact that $\mathrm{Cr}$ is oxidized and the oxide has a bigger lattice parameter than pure $\mathrm{Cr}$ [61]. Nevertheless, a certain presence of $\mathrm{Co}$ in the shell cannot be completely ruled out.
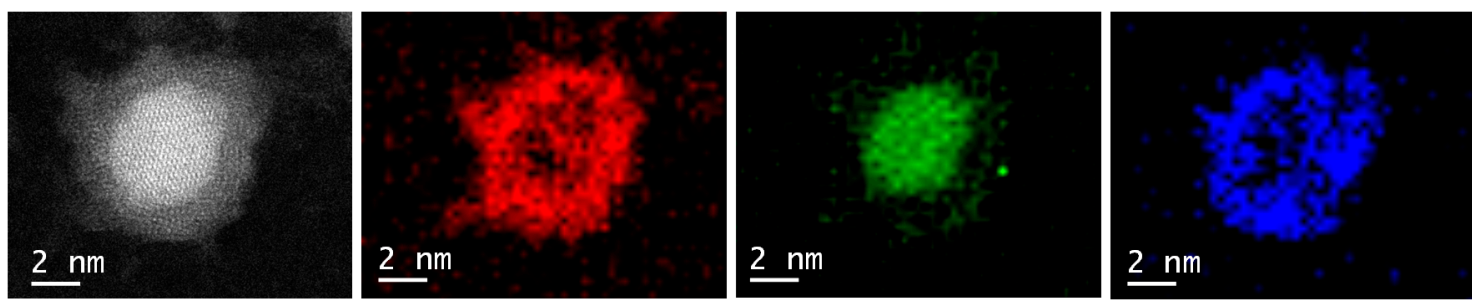

Figure 7. Cs-corrected HR-STEM data corresponding to the CoCr NPs from the $\mathrm{Co}_{80} \mathrm{Cr}_{20}$ target. A high-magnification image is presented together with the corresponding EELS chemical maps.

Line profiles were also extracted from the three samples (see Figure 8). Figure 8a corresponds to the smallest $\mathrm{Co}_{90} \mathrm{Cr}_{10}$ NPs displaying a homogeneous metal distribution (this is no core@shell structures). For the samples with a diameter of $6.9 \mathrm{~nm}$ (Figure $8 \mathrm{~b}, \mathrm{c}$ for $\mathrm{Co}_{90} \mathrm{Cr}_{10}$ and $\mathrm{Co}_{80} \mathrm{Cr}_{20}$, respectively) the core@shell structure is evidenced. For $\mathrm{Co}_{90} \mathrm{Cr}_{10}$, the $\mathrm{Co}$, although mainly centered in the core, is also clearly present in the shell, suggesting that this shell is formed by $\mathrm{Co}, \mathrm{Cr}$, and $\mathrm{O}$. On the other hand, for $\mathrm{Co}_{80} \mathrm{Cr}_{20}$ material the shell is mainly formed by strongly oxidized $\mathrm{Cr}$. The fact the outermost shell is formed by the three compounds for the Co-rich material may explain the larger size of the shell.

The power used for the NP fabrication $(5 \mathrm{~W})$ was nearly three times lower than in the previous case $(14 \mathrm{~W})$. Interestingly, despite this lower applied power to the magnetron, $7 \mathrm{~nm}$ diameter nanoparticles have been obtained. The reason for this could be understood in terms of the higher sputtering yield of $\mathrm{Cr}$, as well as its larger content in the target. In any case, this lower power implies that a smaller thermal energy supplied to the NPs during the fabrication process. However, a thicker shell was 
systematically observed in the TEM analysis of these NPs (see Supplementary Figure S5) and revealed the fact that $\mathrm{Cr}$ diffusion is again highly favored.
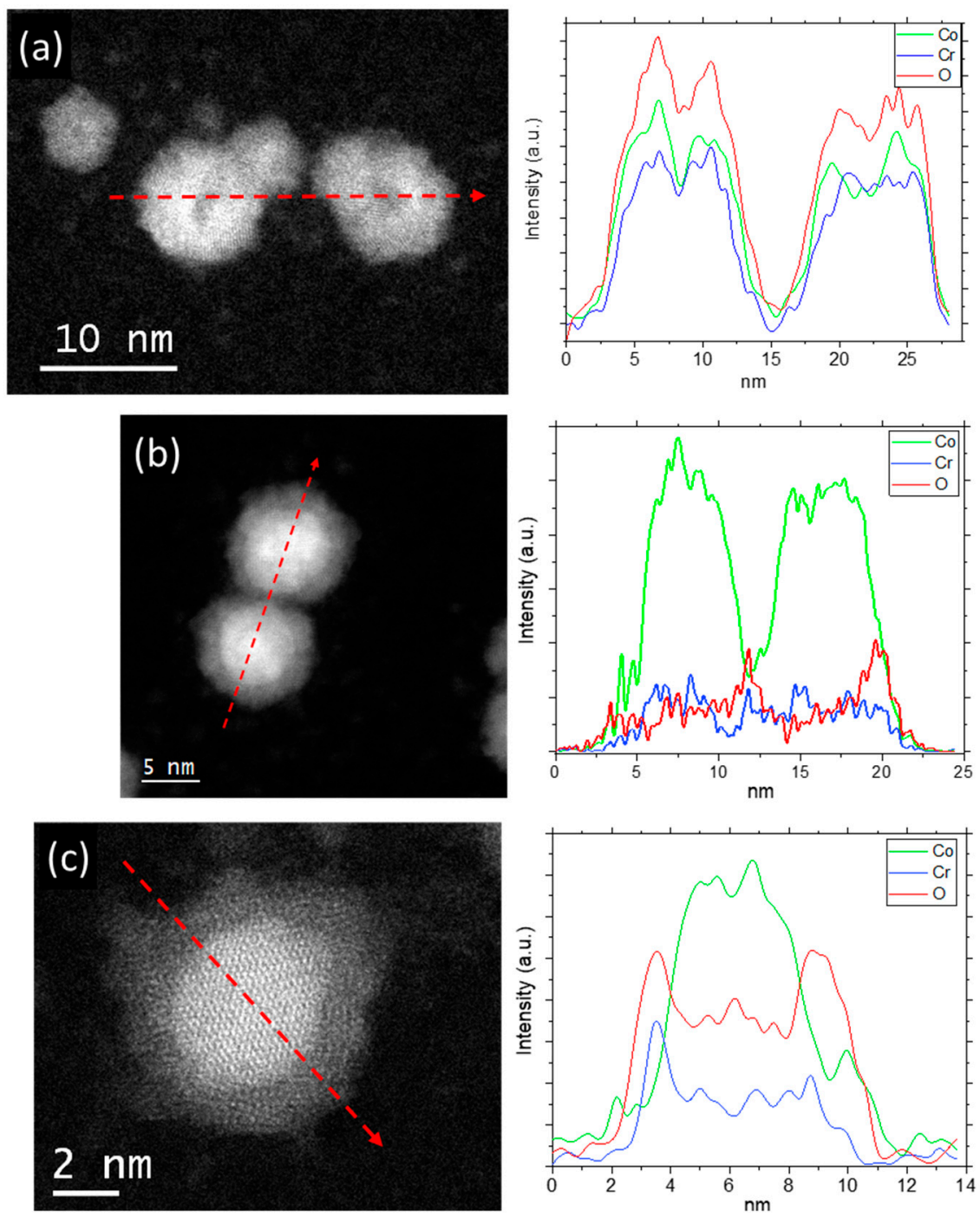

Figure 8. EELS profiles extracted along the red dash arrows corresponding to (a) $\mathrm{Co}_{90} \mathrm{Cr}_{10} 5.6 \mathrm{~nm}$, (b) $\mathrm{Co}_{90} \mathrm{Cr}_{10} 6.9 \mathrm{~nm}$, and (c) $\mathrm{Co}_{80} \mathrm{Cr}_{20} 7 \mathrm{~nm}$.

The well-defined core@shell structure gives us the opportunity to try to access the fundamental magnetic properties of the NPs. Hence, in this case, the magnetic characterization was carried out on samples with less than a monolayer of nanoparticles. This allowed us to reduce the interparticle interaction, leading to a deep understanding of the magnetic properties of the NPs themselves. Nevertheless, a minimal density is needed to gain access to some magnetic signal. The compromise was found in samples with $15 \%$ of a monolayer of nanoparticles.

Figure 9a shows ZCF-FC curves, where the diamagnetic contribution of the Si substrate $\left(\mathrm{M}_{\mathrm{Si}}=5.2 \times 10^{-6} \mathrm{emu}\right)$ has been corrected. In this system, a blocking temperature of $\mathrm{T}_{\mathrm{B}}=70 \pm 10 \mathrm{~K}$ was found (cf. Figure S6), a value that is even higher than reported $T_{B}=50 \mathrm{~K}$ for Co NPs of $10 \mathrm{~nm}$ in diameter [44]. In fact, the $T_{B}$ of these Co@Cr NPs is similar to that expected for Co NPs with a diameter twice as large, which implies a corresponding enhancement of the effective anisotropy in our Co@Cr NPs. Since, for the given surface coverage, dipolar interparticle interactions are expected to have only a moderate effect on the blocking temperature [62], this result is attributed to exchange coupling between the ferromagnetic Co core and an antiferromagnetic shell. 

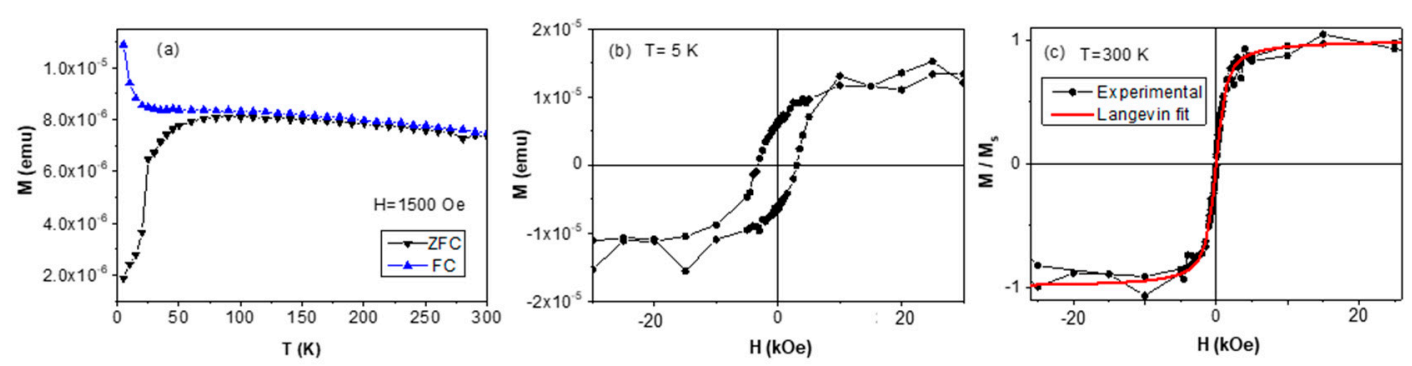

Figure 9. (a) Zero-field cooled-field-cooled (ZFC-FC) curves measured at $\mathrm{H}=1500$ Oe. Hysteresis loop measured after zero-field cooling at (b) $5 \mathrm{~K}$ and (c) $300 \mathrm{~K}$.

The hysteresis loop displayed in Figure 9b, measured at $5 \mathrm{~K}$, shows a coercive field of $\mathrm{H}_{\mathrm{C}}=(3.2 \pm 0.3) \mathrm{kOe}$, approximately 16\% lower than that measured for the Co@Cr NPs produced with the $\mathrm{Co}_{90} \mathrm{Cr}_{10}$ target (Figure 4). The difference can be attributed to both a smaller Co core and a weaker exchange coupling (due to a reduced shell oxidation) in the case of the $\mathrm{Co}_{80} \mathrm{Cr}_{20}$ system.

In contrast, the hysteresis loop at $300 \mathrm{~K}$ (Figure 9c) shows negligible remanence and coercivity, as expected for the superparamagnetic (SP) response indicated by Figure 9a. This SP regime is, in turn, expected from the small diameter estimated above for the Co core $\left(d_{\mathrm{TEM}} \approx 4.3 \mathrm{~nm}\right.$ in diameter), since the critical SP size at RT for a Co NP is $d \approx 9 \mathrm{~nm}[63]$. The magnetic volume $\left(\mathrm{V}_{\mathrm{mag}}\right)$ of the sample can be extracted by fitting the observed SP response to the Langevin function [64,65], obtaining $V_{\mathrm{mag}}=5.3 \pm 0.3 \times 10^{-20} \mathrm{~cm}^{3}$, from which the magnetic diameter $d_{\mathrm{mag}}=4.7 \pm 0.2 \mathrm{~nm}$ follows, in good agreement with $d_{\text {TEM }}$, particularly after taking into account that ignoring the size distribution in a Langevin fit will yield an effective particle moment larger than the mean particle moment of the distribution [62]. Note that the use of the Langevin equation, which assumes a negligible anisotropy barrier compared to the thermal energy, is justified in the first place by the fact that the measurement temperature $(300 \mathrm{~K})$ is more than four times higher than the blocking temperature of any of the samples, the criterion suggested by Mamiya et al. for typical size distributions [66].

Once the size of the Co core has been established, the effective magnetic anisotropy constant of the Co@Cr NPs $\left(\mathrm{K}_{\mathrm{Co} @ \mathrm{Cr}}\right)$ can be extracted from the Néel-Brown law governing the relaxation time of the SP NPs as [13]:

$$
\mathrm{K}_{\mathrm{Co@Cr}}=\frac{25 \times \mathrm{T}_{\mathrm{B}} \times \mathrm{k}_{\mathrm{B}}}{\frac{\pi}{6} \times \mathrm{d}^{3}}=(5.8 \pm 1.2) \times 10^{5} \mathrm{~J} / \mathrm{m}^{3} .
$$

The value obtained nearly doubles the volume anisotropy for FCC Co $\left(\mathrm{K}_{\mathrm{Co}}=2.7 \times 10^{5} \mathrm{~J} / \mathrm{m}^{3}\right)[67]$. As mentioned above, this enhanced value could possibly be due to the existence of an additional contribution to the anisotropy from the exchange coupling between the ferromagnetic core and an antiferromagnetic shell.

\section{Conclusions}

Well-defined Core@shell Co@Cr nanoparticles can be spontaneously formed in the gas phase under certain experimental conditions using alloy targets. Starting from a $\mathrm{Co}_{90} \mathrm{Cr}_{10}$ target, we observe that a minimum NP size is needed to obtain shell formation without further treatments. When the number of atoms at the surface is higher than number of atoms at the volume, there is not enough $\mathrm{Cr}$ to create a shell and only certain Cr segregation is observed. This occurred for the NPs with a mean diameter of $5.6 \mathrm{~nm}$. On the other hand, in the NPs with a mean diameter of $6.9 \mathrm{~nm}$ the number of surface atoms becomes smaller than the volume atoms and a core@shell structure is formed. In this system, a Cr-enriched shell surrounds a Co core. For a similar NP size, when the Cr content is increased (using a $\mathrm{Co}_{80} \mathrm{Cr}_{20}$ target) a thicker $\mathrm{Cr}$ coating is formed, as expected from the higher $\mathrm{Cr}$ content. These results evidenced the tendency of $\mathrm{Cr}$ to migrate towards the surface to form a shell, which subsequently oxidized after air exposure. 
In these conditions, ferromagnetic NPs stable in a wide temperature range (below $300 \mathrm{~K}$ ) are obtained using a $\mathrm{Co}_{90} \mathrm{Cr}_{10}$ target, reducing the critical size for room temperature superparamagnetism to well below $7 \mathrm{~nm}$. This is caused by the enhancement of the total anisotropy due to an exchange bias contribution stemming from the coupling between the different magnetic phases. In the smaller NPs $(5.6 \mathrm{~nm})$, there is a larger presence of interfaces due to the more heterogeneous structure, which favors an increase in the coercive field and the exchange bias. This, together with the dipolar interactions between NPs, is responsible for the hard magnetism at low temperatures and the blocked response at RT. Although the NPs with a larger proportion of $\mathrm{Cr}$ remained superparamagnetic at RT, they present nearly twice as much anisotropy as conventional FCC Co NPs.

Supplementary Materials: The following are available online at http://www.mdpi.com/2673-3501/1/1/7/s1: Figure S1. Scheme of the MICS system for the fabrication of the nanoparticles; Figure S2: ZFC-FC magnetization curves of (a) NPs $d=5.6 \mathrm{~nm}$ at $\mathrm{H}_{\mathrm{apl}}=100 \mathrm{Oe}$ and (b) NPs of $\mathrm{d}=6.9 \mathrm{~nm}$ at $\mathrm{H}_{\mathrm{apl}}=50$ Oe; Figure S3: Evolution of the chemical composition extracted from the wide scan spectra taken at different sputtering times with $\mathrm{Ar}^{+}$; Figure S4: Evolution of the cobalt components with sputtering time; Figure S5: Comparison of the NPs formed from a Co $90 \mathrm{Cr}_{10}$ and $\mathrm{Co}_{80} \mathrm{Cr}_{20}$ target; Figure S6: $\log$ (MFC-MZFC) vs. T of the $\mathrm{Co}_{80} \mathrm{Cr}_{20} 7 \mathrm{~nm}$ NPs. A change in the slope can be observed at $\mathrm{T} \approx 70 \mathrm{~K}$, indicating the blocking temperature.

Author Contributions: Conceptualization, Y.H.; methodology, L.M., E.N., and Y.H.; data acquisition J.S.-M., E.M.J., L.M., Á.M., E.H.S., J.A.D.T., E.N., Y.H.; formal analysis J.S.-M., E.M.J., L.M., Á.M., E.H.S., J.A.D.T., E.N., Y.H.; investigation, J.S.-M. and E.M.J.; writing-original draft preparation, L.M.; writing-review and editing J.S.-M., E.M.J., L.M., Á.M., E.H.S., J.A.D.T., E.N., Y.H.; supervision, Y.H. All authors have read and agreed to the published version of the manuscript.

Funding: This research was funded by the Spanish Ministry of Science, grant number RYC2018-024561-I; the National Natural Science Foundation of China, Grant Number NFSC-21850410448; The Centre for High-resolution Electron Microscopy (C $\hbar \mathrm{EM})$, supported by SPST of ShanghaiTech University under contract No. EM02161943 and NSFC- 21835002; the Spanish MINECO, grant number FIS2016-76058-C4-1-R and MAT2015-65295-R; and the Comunidad de Madrid grant number P2018/NMT-4321.

Conflicts of Interest: The authors declare no conflict of interest.

\section{References}

1. He, L.-B.; Zhang, L.; Tang, L.-P.; Sun, J.; Zhang, Q.-B.; Sun, L.-T. Novel behaviors/properties of nanometals induced by surface effects. Mater. Today Nano 2018, 1, 8-21. [CrossRef]

2. González-Rubio, G.; Mosquera, J.; Kumar, V.; Pedrazo-Tardajos, A.; Llombart, P.; Solís, D.M.; Lobato, I.; Noya, E.G.; Guerrero-Martínez, A.; Taboada, J.M.; et al. Micelle-directed chiral seeded growth on anisotropic gold nanocrystals. Science 2020, 368, 1472-1477. [CrossRef]

3. Seh, Z.W.; Kibsgaard, J.; Dickens, C.F.; Chorkendorff, I.; Nørskov, J.K.; Jaramillo, T.F. Combining theory and experiment in electrocatalysis: Insights into materials design. Science 2017, 355, eaad4998. [CrossRef] [PubMed]

4. Qiu, L.; Zhu, N.; Feng, Y.; Michaelides, E.E.; Żyła, G.; Jing, D.; Zhang, X.; Norris, P.M.; Markides, C.N.; Mahian, O. A review of recent advances in thermophysical properties at the nanoscale: From solid state to colloids. Phys. Rep. 2020, 843,1-81. [CrossRef]

5. Jun, Y.-W.; Seo, J.-W.; Cheon, J. Nanoscaling Laws of Magnetic Nanoparticles and Their Applicabilities in Biomedical Sciences. Acc. Chem. Res. 2008, 41, 179-189. [CrossRef]

6. Binns, C.; Trohidou, K.N.; Bansmann, J.; Baker, S.H.; A Blackman, J.; Bucher, J.-P.; Kechrakos, D.; Kleibert, A.; Louch, S.; Meiwes-Broer, K.-H.; et al. The behaviour of nanostructured magnetic materials produced by depositing gas-phase nanoparticles. J. Phys. D Appl. Phys. 2005, 38, R357-R379. [CrossRef]

7. De Toro, J.A.; Vasilakaki, M.; Lee, S.S.; Andersson, M.S.; Normile, P.S.; Yaacoub, N.; Murray, P.D.; Sánchez, E.H.; Muñiz, P.; Peddis, D.; et al. Remanence Plots as a Probe of Spin Disorder in Magnetic Nanoparticles. Chem. Mater. 2017, 29, 8258-8268. [CrossRef]

8. Bucher, J.P.; Douglass, D.C.; Bloomfield, L.A. Magnetic properties of free cobalt clusters. Phys. Rev. Lett. 1991, 66, 3052-3055. [CrossRef]

9. Suzuki, M.; Muraoka, H.; Inaba, Y.; Miyagawa, H.; Kawamura, N.; Shimatsu, T.; Maruyama, H.; Ishimatsu, N.; Isohama, Y.; Sonobe, Y. Depth profile of spin and orbital magnetic moments in a subnanometer Pt film on Co. Phys. Rev. B 2005, 72, 54430. [CrossRef] 
10. Edmonds, K.W.; Binns, C.; Baker, S.; Maher, M.; Thornton, S.; Tjernberg, O.; Brookes, N.B. Magnetism of exposed and Co-capped Fe nanoparticles. J. Magn. Magn. Mater. 2000, 220, 25-30. [CrossRef]

11. Baker, S.; Binns, C.; Edmonds, K.W.; Maher, M.; Thornton, S.; Louch, S.; Dhesi, S. Enhancements in magnetic moments of exposed and Co-coated Fe nanoclusters as a function of cluster size. J. Magn. Magn. Mater. 2002, 247, 19-25. [CrossRef]

12. Popok, V.; Kylian, O. Gas-Phase Synthesis of Functional Nanomaterials. Appl. Nano 2020, 1, 25-58. [CrossRef]

13. Blundell, S. Magnetism in Condensed Matter; Oxford University Press: Oxford, UK, 2001; ISBN 9780198505914.

14. Baibich, M.N.; Broto, J.M.; Fert, A.; Van Dau, F.N.; Petroff, F.; Etienne, P.; Creuzet, G.; Friederich, A.; Chazelas, J. Giant Magnetoresistance of (001)Fe/(001)Cr Magnetic Superlattices. Phys. Rev. Lett. 1988, 61, 2472-2475. [CrossRef]

15. Binasch, G.; Grünberg, P.; Saurenbach, F.; Zinn, W. Enhanced magnetoresistance in layered magnetic structures with antiferromagnetic interlayer exchange. Phys. Rev. B 1989, 39, 4828-4830. [CrossRef]

16. Skumryev, V.; Stoyanov, S.; Zhang, Y.; Hadjipanayis, G.; Givord, D.; Nogués, J. Beating the superparamagnetic limit with exchange bias. Nat. Cell Biol. 2003, 423, 850-853. [CrossRef]

17. Sato, N. Structure and magnetism of Co-Cr thin films with an artificial superlattice structure. J. Appl. Phys. 1987, 61, 1979-1989. [CrossRef]

18. Morikawa, T.; Suzuki, M.; Taga, Y. Soft magnetic properties of Co-Cr-O granular films. J. Appl. Phys. 1998, 83, 6664-6666. [CrossRef]

19. Fallarino, L.; Kirby, B.J.; Pancaldi, M.; Riego, P.; Balk, A.L.; Miller, C.W.; Vavassori, P.; Berger, A. Magnetic properties of epitaxial CoCr films with depth-dependent exchange-coupling profiles. Phys. Rev. B 2017, 95, 134445. [CrossRef]

20. Öztürk, M.; Demirci, E.; Erkovan, M.; Öztürk, O.; Akdoğan, N. Coexistence of perpendicular and in-plane exchange bias using a single ferromagnetic layer in $\mathrm{Pt} / \mathrm{Co} / \mathrm{Cr} / \mathrm{CoO}$ thin film. EPL Europhys. Lett. 2016, 114, 17008. [CrossRef]

21. Cui, B.; Li, D.; Yun, J.; Zuo, Y.; Guo, X.; Wu, K.; Zhang, X.; Wang, Y.; Xi, L.; Xue, D. Magnetization switching through domain wall motion in $\mathrm{Pt} / \mathrm{Co} / \mathrm{Cr}$ racetracks with the assistance of the accompanying Joule heating effect. Phys. Chem. Chem. Phys. 2018, 20, 9904-9909. [CrossRef] [PubMed]

22. Petr, M.; Kylián, O.; Kuzminova, A.; Kratochvíl, J.; Khalakhan, I.; Hanuš, J.; Biederman, H. Noble metal nanostructures for double plasmon resonance with tunable properties. Opt. Mater. 2017, 64, $276-281$. [CrossRef]

23. Zhao, J.; Mayoral, A.; Martínez, L.; Johansson, M.P.; Djurabekova, F.; Huttel, Y. Core-Satellite Gold Nanoparticle Complexes Grown by Inert Gas-Phase Condensation. J. Phys. Chem. C 2020. [CrossRef] [PubMed]

24. Haberland, H.; Karrais, M.; Mall, M. A new type of cluster and cluster ion source. Eur. Phys. J. D 1991, 20, 413-415. [CrossRef]

25. Martínez, L.; Díaz, M.; Román, E.; Ruano, M.; P., D.L.; Huttel, Y. Generation of Nanoparticles with Adjustable Size and Controlled Stoichiometry: Recent Advances. Langmuir 2012, 28, 11241-11249. [CrossRef]

26. Llamosa, D.; Ruano, M.; Martínez, L.; Mayoral, A.; Roman, E.; García-Hernández, M.; Huttel, Y. The ultimate step towards a tailored engineering of core@shell and core@shell@shell nanoparticles. Nanoscale 2014, 6, 13483-13486. [CrossRef] [PubMed]

27. Spadaro, M.C.; Humphrey, J.J.L.; Cai, R.; Martínez, L.; Haigh, S.J.; Huttel, Y.; Spencer, S.J.; Wain, A.J.; Palmer, R. Electrocatalytic Behavior of PtCu Clusters Produced by Nanoparticle Beam Deposition. J. Phys. Chem. C 2020. [CrossRef] [PubMed]

28. Horcas, I.; Fernández, R.; Gómez-Rodríguez, J.M.; Colchero, J.; Gómez-Herrero, J.; Baro, A.M. WSXM: A software for scanning probe microscopy and a tool for nanotechnology. Rev. Sci. Instrum. 2007, 78, 013705. [CrossRef]

29. Briggs, D. Handbook of X-ray Photoelectron Spectroscopy C. D. Wanger, W. M. Riggs, L. E. Davis, J. F. Moulder and G. E.Muilenberg Perkin-Elmer Corp., Physical Electronics Division, Eden Prairie, Minnesota, USA, 1979. 190 pp. \$195. Surf. Interface Anal. 1981, 3. [CrossRef]

30. Krishnan, G.; Verheijen, M.A.; Brink, G.H.T.; Palasantzas, G.; Kooi, B.J. Tuning structural motifs and alloying of bulk immiscible Mo-Cu bimetallic nanoparticles by gas-phase synthesis. Nanoscale 2013, 5, 5375-5383. [CrossRef] 
31. Shyjumon, I.; Gopinadhan, M.; Helm, C.A.; Smirnov, B.M.; Hippler, R. Deposition of titanium/titanium oxide clusters produced by magnetron sputtering. Thin Solid Films 2006, 500, 41-51. [CrossRef]

32. Perez, D.L.; Martínez, L.; Huttel, Y.; Nez, L. Martí Multiple Ion Cluster Source for the Generation of Magnetic Nanoparticles: Investigation of the Efficiency as a Function of the Working Parameters for the Case of Cobalt. Dataset Pap. Sci. 2014, 2014, 1-9. [CrossRef]

33. Ruano, M.; Huttel, Y.; Nez, L. Martí Investigation of the Working Parameters of a Single Magnetron of a Multiple Ion Cluster Source: Determination of the Relative Influence of the Parameters on the Size and Density of Nanoparticles. Dataset Pap. Sci. 2013, 2013, 1-8. [CrossRef]

34. Mayoral, A.; Mejía-Rosales, S.; Mariscal, M.M.; Pérez-Tijerina, E.; Jose-Yacaman, M. The Co-Au interface in bimetallic nanoparticles: A high resolution STEM study. Nanoscale 2010, 2, 2647. [CrossRef]

35. Binns, C.; Prieto, P.; Baker, S.; Howes, P.; Dondi, R.; A Burley, G.; Lari, L.; Kröger, R.; Pratt, A.; Aktas, S.; et al. Preparation of hydrosol suspensions of elemental and core-shell nanoparticles by co-deposition with water vapour from the gas-phase in ultra-high vacuum conditions. J. Nanoparticle Res. 2012, 14, 1-16. [CrossRef]

36. Pérez, D.L.; Espinosa, A.; Martínez-Orellana, L.; Román, E.; Ballesteros, C.; Mayoral, A.; García, E.L.R.; Huttel, Y. Thermal Diffusion at Nanoscale: From CoAu Alloy Nanoparticles to Co@Au Core/Shell Structures. J. Phys. Chem. C 2013, 117, 3101-3108. [CrossRef]

37. Koten, M.A.; Mukherjee, P.; Shield, J.E. Core-Shell Nanoparticles Driven by Surface Energy Differences in the Co-Ag, W-Fe, and Mo-Co Systems. Part. Part. Syst. Charact. 2015, 32, 848-853. [CrossRef]

38. Peng, L.; Ringe, E.; Van Duyne, R.P.; Marks, L. Segregation in bimetallic nanoparticles. Phys. Chem. Chem. Phys. 2015, 17, 27940-27951. [CrossRef]

39. Palomares-Baez, J.-P.; Panizon, E.; Ferrando, R. Nanoscale Effects on Phase Separation. Nano Lett. 2017, 17, 5394-5401. [CrossRef]

40. Xu, Y.-H.; Wang, J.-P. Direct Gas-Phase Synthesis of Heterostructured Nanoparticles through Phase Separation and Surface Segregation. Adv. Mater. 2008, 20, 994-999. [CrossRef]

41. Xu, Y.-H.; Wang, J.-P. Magnetic Properties of Heterostructured Co-Au Nanoparticles Direct-Synthesized from Gas Phase. IEEE Trans. Magn. 2007, 43, 3109-3111. [CrossRef]

42. Vernieres, J.; Steinhauer, S.; Zhao, J.; Chapelle, A.; Menini, P.; Dufour, N.; Diaz, R.E.; Nordlund, K.; Djurabekova, F.; Grammatikopoulos, P.; et al. Gas Phase Synthesis of Multifunctional Fe-Based Nanocubes. Adv. Funct. Mater. 2017, 27, 1605328. [CrossRef]

43. Kashtanov, P.V.; Smirnov, B.M.; Hippler, R. Magnetron plasma and nanotechnology. Phys. Uspekhi 2007, 50, 455. [CrossRef]

44. Ruano, M.; Diaz, M.; Martinez, L.; Navarro, E.; Roman, E.; Garcia-Hernandez, M.; Espinosa, A.; Ballesteros, C.I.; Fermento, R.; Huttel, Y. Matrix and interaction effects on the magnetic properties of Co nanoparticles embedded in gold and vanadium. Phys. Chem. Chem. Phys. 2013, 15, 316-329. [CrossRef] [PubMed]

45. Andersson, M.S.; Mathieu, R.; Lee, S.S.; Normile, P.S.; Singh, G.; Nordblad, P.; De Toro, J.A. Size-dependent surface effects in maghemite nanoparticles and its impact on interparticle interactions in dense assemblies. Nanotechnology 2015, 26, 475703. [CrossRef]

46. Sanchez, E.H.; Vasilakaki, M.; Lee, S.S.; Normile, P.S.; Muscas, G.; Murgia, M.; Andersson, M.S.; Singh, G.; Mathieu, R.; Nordblad, P.; et al. Simultaneous Individual and Dipolar Collective Properties in Binary Assemblies of Magnetic Nanoparticles. Chem. Mater. 2020, 32, 969-981. [CrossRef]

47. López-Ortega, A.; Estrader, M.; Salazar-Alvarez, G.; Roca, A.G.; Nogués, J. Applications of exchange coupled bi-magnetic hard/soft and soft/hard magnetic core/shell nanoparticles. Phys. Rep. 2015, 553, 1-32. [CrossRef]

48. Nogués, J.; Skumryev, V.; Sort, J.; Stoyanov, S.; Givord, D. Shell-Driven Magnetic Stability in Core-Shell Nanoparticles. Phys. Rev. Lett. 2006, 97, 157203. [CrossRef]

49. Coey, J.M.D. Magnetism and Magnetic Materials; Cambridge University Press: Cambridge, UK, 2010.

50. De Toro, J.A.; Andrés, J.P.; Gonzalez, J.A.; Muñiz, P.; Riveiro, J.M. The oxidation of metal-capped Co cluster films under ambient conditions. Nanotechnology 2009, 20, 085710. [CrossRef]

51. Normile, P.S.; De Toro, J.A.; Muñoz, T.; Gonzalez, J.A.; Andrés, J.P.; Muñiz, P.; Escobar-Galindo, R.; Riveiro, J.M. Influence of spacer layer morphology on the exchange-bias properties of reactively sputteredCo/Agmultilayers. Phys. Rev. B 2007, 76, 104430. [CrossRef]

52. Nogues, J.; Sort, J.; Langlais, V.; Skumryev, V.; Suriñach, S.; Muñoz, J.; Baró, M. Exchange bias in nanostructures. Phys. Rep. 2005, 422, 65-117. [CrossRef] 
53. Kalska-Szostko, B.; Fumagalli, P.; Hilgendorff, M.; Giersig, M. Co/CoO core-shell nanoparticles-Temperaturedependent magneto-optic studies. Mater. Chem. Phys. 2008, 112, 1129-1132. [CrossRef]

54. Martín-González, M.; Huttel, Y.; Cebollada, A.; Reig, G.A.; Briones, F. Surface localized nitrogen incorporation in epitaxial FePd films and its effect in the Magneto-Optical properties. Surf. Sci. 2004, 571, 63-73. [CrossRef]

55. Surviliene, S. The use of XPS for study of the surface layers of $\mathrm{Cr}$-Co alloy electrodeposited from $\mathrm{Cr}$ (III) formate-urea baths. Solid State Ion. 2008, 179, 222-227. [CrossRef]

56. Dupin, J.-C.; Gonbeau, D.; Vinatier, P.; Levasseur, A. Systematic XPS studies of metal oxides, hydroxides and peroxides. Phys. Chem. Chem. Phys. 2000, 2, 1319-1324. [CrossRef]

57. La Rosa-Toro, A.; Berenguer, R.; Quijada, C.; Montilla, F.; Morallón, E.; Vázquez, J.L. Preparation and Characterization of Copper-Doped Cobalt Oxide Electrodes. J. Phys. Chem. B 2006, 110, 24021-24029. [CrossRef]

58. Hosseini, S.A.; Alvarez-Galvan, M.; Fierro, J.; Niaei, A.; Salari, D. MCr2O4 (M=Co, Cu, and Zn) nanospinels for 2-propanol combustion: Correlation of structural properties with catalytic performance and stability. Ceram. Int. 2013, 39, 9253-9261. [CrossRef]

59. Rosa, W.O.; Martínez, L.; Jaafar, M.; Asenjo, A.; Vázquez, M. Asymmetric magnetization reversal process in Co nanohill arrays. J. Appl. Phys. 2009, 106, 103906. [CrossRef]

60. Tsustumi, Y.; Doi, H.; Nomura, N.; Ashida, M.; Chen, P.; Kawasaki, A.; Hanawa, T. Surface Composition and Corrosion Resistance of Co-Cr Alloys Containing High Chromium. Mater. Trans. 2016, 57, 2033-2040. [CrossRef]

61. Abdullah, M.M.; Rajab, F.M.; Al-Abbas, S.M. Structural and optical characterization of Cr2O3 nanostructures: Evaluation of its dielectric properties. AIP Adv. 2014, 4, 027121. [CrossRef]

62. De Toro, J.A.; Gonzalez, J.A.; Normile, P.S.; Muñiz, P.; Andrés, J.P.; Antón, R.L.; Canales-Vázquez, J.; Riveiro, J.M. Energy barrier enhancement by weak magnetic interactions in $\mathrm{Co} / \mathrm{Nb}$ granular films assembled by inert gas condensation. Phys. Rev. B 2012, 85, 054429. [CrossRef]

63. Llamosa Pérez, D. Fabricación y Estudio de las Propiedades Físicas de Nanopartículas de Aleación, Núcleo@corteza y Núcleo@corteza@corteza Basadas en Co, Au y Ag; Universidad Autónoma de Madrid: Madrid, Spain, 2014.

64. Shiratsuchi, Y.; Yamamoto, M.; Endo, Y.; Li, D.; Bader, S.D. Superparamagnetic behavior of ultrathin Fe films grown on $\mathrm{Al}_{2} \mathrm{O}_{3}(0001)$ substrates. J. Appl. Phys. 2003, 94, 7675-7679. [CrossRef]

65. Tamion, A.; Hillenkamp, M.; Tournus, F.; Bonet, E.; Dupuis, V. Accurate determination of the magnetic anisotropy in cluster-assembled nanostructures. Appl. Phys. Lett. 2009, 95, 62503. [CrossRef]

66. Mamiya, H.; Nakatani, I.; Furubayashi, T.; Ohnuma, M. Analyses of Superparamagnetism-Magnetic Properties of Isolated Iron -Nitride Nanoparticles. Trans. Magn. Soc. Jpn. 2002, 2, 36-48. [CrossRef]

67. Chen, J.-P.; Sorensen, C.M.; Klabunde, K.J.; Hadjipanayis, G.C. Magnetic properties of nanophase cobalt particles synthesized in inversed micelles. J. Appl. Phys. 1994, 76, 6316-6318. [CrossRef]

Publisher's Note: MDPI stays neutral with regard to jurisdictional claims in published maps and institutional affiliations.

(C) 2020 by the authors. Licensee MDPI, Basel, Switzerland. This article is an open access article distributed under the terms and conditions of the Creative Commons Attribution (CC BY) license (http://creativecommons.org/licenses/by/4.0/). 